\title{
HIFU ablation is not a proven standard treatment for localized prostate cancer
}

\author{
Alan I. So, MD, FRCSC \\ Department of Urologic Sciences, Vancouver Prostate Centre, University of British Columbia, Vancouver, BC
}

Cite as: Can Urol Assoc J 201 1;5(6):424-6; hrtp://dx.doi.org/10.5489/cuaj.11232

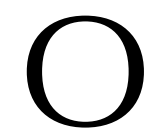
ptimal management of clinically significant localized prostate cancer centres on the achievement of the prostate cancer "trifecta" : (1) cure of malignancy; (2) preservation of erectile function; and (3) maintenance of voiding function and continence. ${ }^{1}$ Although in use since the mid-1990s, high-intensity focused ultrasound (HIFU) as an ablative source to treat prostate cancer has not been clearly demonstrated to be advantageous in any of these parameters compared to already established therapies, including surgical (radical prostatectomy) and radiation (brachytherapy) options. Interestingly, the lack of robust clinical evidence showing a benefit, or even equivalence, of HIFU in comparison to standard therapies is the primary reason why the European Association of Urology, ${ }^{2}$ the American Urologic Association, ${ }^{3}$ National Comprehensive Cancer Network, ${ }^{4}$ the UK National Health Service based National Institute for Health and Clinical Excellence Prostate Cancer guidelines ${ }^{5}$ and the US Federal Drug Administration do not currently recommend HIFU as a standard option for the initial management of clinically localized prostate cancer.

Recently four different systematic reviews assessing the role of HIFU in prostate cancer have been published. ${ }^{6-10}$ As emphasized in these reviews, the level of evidence assessing efficacy outcomes of HIFU is "very low" with "serious limitations" in data analysis. ${ }^{6-10}$ Efficacy analyses are limited since all published studies to date are observational series; there are no phase II or III clinical trials that have been published comparing HIFU with radical prostatectomy, radiotherapy (either brachytherapy or external beam) or active surveillance. Hence, there is no evidence to show that HIFU improves or provides equivalent oncologic outcomes, whether in reference to progression-free survival, biochemical-free survival or overall survival. Accordingly, there is a lack of evidence to demonstrate that HIFU offers an improved side effect profile compared to surgery or radiation. Unfortunately, most HIFU series have short followup, and although over 20 observational series have been reported, most have been performed by a small number of different study groups suggesting the possibility of publication bias. ${ }^{9}$

Several study confounders also limit the usefulness of HIFU literature making efficacy analyses and side effect profile comparisons between HIFU and other modalities challenging. Studies have used two different HIFU technologies (Sonoblate, Focus Surgery Inc., Indianapolis, IN and Ablatherm, EDAP TMS SA, Vaulx-enVelin, France) that have different methodologies, treatment protocols and inclusion/exclusion criteria. ${ }^{9}$ Although retreatment rates have been reported in HIFU series ranging from $7.7 \%$ to $43 \%$, these traditionally have not been defined in HIFU literature as "treatment failures."11 This exclusion complicates any attempt to compare endpoints, such as biochemical failure and progression-free survival, with other modalities that traditionally includes retreatment of any form as a treatment failure. In fact, there is little evidence to define the indications or contraindications of retreatment and sparse data revealing the safe limits of retreatments. Making endpoint comparison between modalities even more difficult is the heterogeneous definition of biochemical failure within the HIFU literature, with some series using radiation-validated prostate-specific antigen failure criteria (Phoenix and ASTRO criteria) and others reporting criteria specifically developed, but not yet validated, for HIFU (Stuttgart definition). ${ }^{12-14}$

Until a validated definition of biochemical failure is defined, HIFU treated patients must be followed with posttreatment transrectal ultrasound-guided prostate biopsy. ${ }^{15}$ Results from HIFU series reveal post-treatment positive biopsy rates that range from $4.9 \%$ to $65 \% .^{6-10}$ Even more worrisome is the growing trend of apical sparing HIFU treatments to reduce damage to the external sphincter. ${ }^{15-18}$ Recently, reports by Boutier and colleagues analyzing the location of 
tumours in HIFU-treatment failures showed that apical-sparing techniques may be associated with higher rates of apical failure. ${ }^{15}$ Routine post-treatment biopsy in 99 consecutive patients found malignancy in $36 \%$, with $60 \%$ of tumours found in the apex. In addition, $21 \%$ of patients developed tumours in locations that were negative pre-treatment, raising concerns for any type of prostate-sparing treatments using pre-treatment biopsy to guide template determination.

These positive biopsy rates show that a considerable number of patients will continue to harbour malignancy within their prostates; however, the impact of HIFU on the efficacy and safety of secondary salvage treatment is unclear. The detrimental effects of HIFU on further treatment were revealed in the only report of post-HIFU salvage prostatectomy by Lawrentshuk and colleagues, in which 15 men, initially with T1C-low and intermediate risk (9 with GS 3, 6 with GS 7) prostate cancer, were treated with non-nerve sparing salvage prostatectomy for HIFU failure. ${ }^{19}$ Analysis of prostatectomy specimens reveals that $27 \%$ had positive margins, $67 \%$ had extracapsular extension, and 53\% had pathologic upgrading compared to pre-HIFU biopsy. ${ }^{19}$ Within this group, two patients had biochemical failure within 12 months of surgery requiring androgen deprivation therapy. Currently, there are no long-term published data from salvage external-beam series, but there are many reports that show that the combination of radiation and HIFU has a significant impact on erectile function and continence. $^{20,21}$ For example, the largest series assessing salvage radiation therapy post-HIFU shows that erectile dysfunction increased from $14 \%$ pre-HIFU, to $51.9 \%$ post-HIFU, followed by $82.3 \%$ post-salvage radiotherapy; this suggests the additive detrimental effects on erectile function. ${ }^{20}$ Obviously, further search is required to assess the efficacy and safety in the treatment of HIFU failures, in which a significant number of patients may harbour clinically significant cancers. In addition, patients should not receive HIFU assuming that this "non-invasive" treatment can be treated easily with surgery or radiation if the treatment fails.

Finally, there is no clear evidence that HIFU treatment provides improved quality of life or improves long-term morbidity compared to either surgery or radiation. Yet, HIFU treatment centres statements such as "[t]reatment by HIFU, however, results in less side effects including incontinence and impotence..."22 and "HIFU using the Sonablate 500 carries little risk of side effects like impotence and incontinence." ${ }^{23}$ Unfortunately, HIFU is not free of short- and longterm side effects. Large systematic reviews reveal that side effects include urinary retention (1\%-8.8\%), erectile dysfunction (20\%-77\%) and urinary incontinence (10\%-49.7\%). ${ }^{6-10}$ Other reported complications include urethra-rectal fistulae $(0-5.6 \%)$, urethral stenosis $(1 \%-17 \%)$, urethral stricture $(1.8 \%-24 \%)$ and chronic perineal pain $(0.9 \%-13.4 \%){ }^{6-10}$
Patients deserve efficacious oncologic treatments that provide minimal impact in quality of life, as well as providing minimal morbidity. However, there is no clear evidence that HIFU provides equivalent oncologic outcomes or improves long-term side effect profile when compared to surgery or brachytherapy. High-intensity focused ultrasound treatment must be evaluated more thoroughly to ensure that cancer outcomes and long-term quality of life are not compromised. Thus, HIFU should remain a treatment that is used in the context of a clinical trial and should not be considered a standard treatment option for men with localized prostate cancer.

Competing interests: None declared.

This paper has been peer-reviewed.

\section{References}

1. Bianco FJ Jr, Scardino PT, Eastham JA. Radical prostatectomy: long-term cancer control and recovery of sexual and urinary function ("trifecta"). Urology 2005;66(5 Suppl):83-94.

2. Heidenreich $A$, Bellmunt J, Bolla $M$, et al. EAU guidelines on prostate cancer. Part 1 : screening, diagnosis, and treatment of clinically localised disease. Eur Urol 2011;59:61-71.

3. Thompson I, Thrasher JB, Aus G, et al. Prostate Cancer: Guideline for the Management of Clinically Localized Prostate Cancer. (Validity updated 2011). hittp://www.auanet.org/content/clinical-practice-guidelines/ clinical-guidelines/main-reports/proscan07/content.pdf. Accessed November 29, 2011.

4. Mohler J, Bahnson RR, Boston B, et al. NCCN clinical practice guidelines in oncology: prostate cancer. J Natl Compr Canc Netw 2010;8:162-200.

5. Graham J, Baker M, Macbeth F, et al. Prostate Cancer: diagnosis and treatment; 2008. http://www. nice.org.uk/nicemedia/pdf/CG58NICEGuideline.pdf. Accessed November 29, 2011.

6. Lukka H, Waldron T, Chin J, et al. High-intensity focused ultrasound for prostate cancer: a practice guideline. Can Urol Assoc J 2010;4:232-6.

7. Lukka H, Waldron T, Chin J, et al. High-intensity focused ultrasound for prostate cancer: a systematic review. Clin Oncol (R Coll Radiol) 2011;23:117-27.

8. Rebillard X, Soulié M, Chartier-Kastler E, et al. High-intensity focused ultrasound in prostate cancer; a systematic literature review of the French Association of Urology. BJU Int 2008;101:1205-13.

9. Warmuth M, Johansson T, Mad P. Systematic review of the efficacy and safety of high-intensity focussed ultrasound for the primary and salvage treatment of prostate cancer. Eur Urol 2010;58:803-15.

10. Pickles T, Goldenberg L, Steinhoff G. Technology review: high-intensity focused ultrasound for prostate cancer. Can J Urol 2005; 12:2593-7.

11. Berge V. Editorial comment to transrectal high-intensity focused ultrasound for treatment of localized prostate cancer. Int J Urol 2011;18:363-4.

12. Blana A, Brown SC, Chaussy C, et al. High-intensity focused ultrasound for prostate cancer: comparative definitions of biochemical failure. BJU Int 2009;104:1058-62.

13. Consensus statement: guidelines for PSA following radiation therapy. American Society for Therapeutic Radiology and Oncology Consensus Panel. Int J Radiat Oncol Biol Phys 1997;37:1035-41.

14. Roach M 3rd, Hanks G, Thames H Jr, et al. Defining biochemical failure following radiotherapy with or without hormonal therapy in men with clinically localized prostate cancer: recommendations of the RTOG-ASTRO Phoenix Consensus Conference. Int I Radiat Oncol Biol Phys 2006;65:965-74.

15. Boutier $R$, Girouin $N$, Cheikh $A B$, et al. Location of residual cancer after transrectal high-intensity focused ultrasound ablation for clinically localized prostate cancer. BJU Int 2011;108:1776-81. doi: 10.1111/j.1464-410X.2011.10251.x. Epub 2011 Jun 28.

16. Blana A, Rogenhofer $S$, Ganzer R, et al. Eight years' experience with high-intensity focused ultrasonography for treatment of localized prostate cancer. Urology 2008;72:1329-33; discussion 1333-4.

17. Beerlage HP, van Leenders $\mathrm{GJ}$, Oosterhof $\mathrm{GO}$, et al. High-intensity focused ultrasound (HIFU) followed after one to two weeks by radical retropubic prostatectomy: results of a prospective study. Prostate 1999;39:41-6. 
18. Poissonnier L, Chapelon JY, Rouvière 0 , et al. Control of prostate cancer by transrectal HIFU in 227 patients. Eur Urol 2007;51:381-7.

19. Lawrentschuk N, Finelli A, Van der Kwast TH, et al. Salvage radical prostatectomy following primary high intensity focused ultrasound for treatment of prostate cancer. J Urol 2011;185:862-8.

20. Riviere J, Bernhard JC, Robert G, et al. Salvage radiotherapy after high-intensity focussed ultrasound for recurrent localised prostate cancer. Eur Urol 2010;58:567-73.

21. Berge V, Baco E, Karlsen SJ. A prospective study of salvage high-intensity focused ultrasound for locally radiorecurrent prostate cancer: early results. Scand I Urol Nephrol 2010;44:223-7.
22. Maple Leaf HIFU. http://www.hifu.ca/patients-prostate-cancer-treatment-options.htm. Accessed November 29, 2011.

23. Can-Am-HIFU. http://www.can-amhifu.com/index.php?option=com_content\&task=view\&id=20\&ltem $\mathrm{id}=63$. Accessed November 29, 2011.

Correspondence: Dr. Alan So, Assistant Professor, Department of Urologic Sciences, Vancouver Prostate Centre, University of British Columbia, Level 6-DHCC, 2775-Laurel St, Vancouver, BC V5Z 1M9; fax: 604-875-5604; alan.so@ubc.ca 